\title{
Why Psychiatric Education Needs the Humanities
}

\author{
Steven C. Schlozman ${ }^{1}$ iD \\ Received: 8 September 2017 / Accepted: 12 September 2017 / Published online: 16 October 2017 \\ (C) Academic Psychiatry 2017
}

Some medical educators have argued for the inclusion of the Humanities in medical education with nothing short of pedagogic passion. These educators see the Humanities as essential to helping physicians to better express empathic connections with their patients, with themselves, and with the cultures in which they practice [1]. Others, however, have argued with equal fervor that a formal and structured inquiry into the humanities has no proper role in medical teaching. They argue that medicine is a trade that by definition differentiates itself from the more abstract pursuits that are necessarily the focus of the Humanities. The polarization of these points of view is perhaps less pronounced among psychiatric investigators, but there is still more than a little disagreement [2]. Indeed, it is striking that the relatively standardized curriculum of formal medical learning should have such opposing opinions. These differences accentuate some of the most fundamental dichotomies among prominent medical educators in the USA and throughout the world.

However, the issue need not be so stringently dichotomous. Questioning whether the Humanities should be part of medical education and especially part of psychiatric education is not really the issue. After all, the Humanities encompass the many modalities by which we as a species artistically represent our fundamental humanity. Given that a central focus of doctoring is to understand the experience of being human, both in sickness and in health, the practice of medicine and the study of the Humanities naturally coincide. One cannot be a physician without at least an implicit acknowledgement of the role that the Humanities play in the ways that we as a

Steven C. Schlozman

sschlozman@partners.org

1 Harvard Medical School, Boston, MA, USA culture define what it means to be human in the first place. The practice of medicine thus permits, provokes, inspires, and rebuffs the very ideas that the Humanities afford. Scholars of the Humanities are quick to note that art, music, drama, literature, dance, philosophy, and even religion cannot help but to factor into the professional and personal identities of physicians. Again, one can argue that this is especially the case for psychiatrists.

Still, in order to make the case that there is a role for the Humanities in medicine and psychiatry, we need to consider a number of very practical questions:

1. How do we define the Humanities?

2. How do the Humanities contribute to health?

3. What can the Humanities offer our students towards becoming more competent physicians?

For the purposes of this journal, we especially need to question how an active and intellectually stimulating Humanities curriculum contributes to the competency and efficacy of the modern psychiatrist.

\section{Defining the Humanities}

The modern study of Humanities in western education is a renaissance phenomenon. It came about as a revitalization of the careful attention paid throughout antiquity to drama, philosophy, art, and religion. In this sense, the study of the Humanities, referred to as studia humantatis, has its initial roots in the Classical Period. Apollo himself was the god of music, poetry, and medicine. The scholars of antiquity understood well the relationships between art and health [3].

During this Renaissance revival, humanistic pursuits expanded to include literature, drama, poetry, law, theology, 
and ethics [3]. Because medical education took place in the same halls as these Renaissance studies, western physicians were universally versed in the Humanities. To understand how much this differs from today's educational philosophy, it is important to note that the pedagogic construct separating the Humanities from science and related fields is relatively new. da Vinci was of course a prodigious artist and a champion anatomist. He was clear in his convictions that these disciplines were essential to one another [4]. Even later, during the relatively regimented intellectual categories that characterized Victorian thinking, substantial emphasis was placed on studying the Humanities and medicine together. In 1853, the newly formed American Medical Association urged its followers to "include the Humanities... and the natural sciences in medical requirements" [5].

There is clearly a long and celebrated history of combining medical education with the pursuit of the Humanities. Furthermore, modern interdisciplinary collaborations have yielded strong evidence for these Renaissance and Victorian convictions. For example, Willamon and colleagues at the Royal College of Music have collaborated with Imperial College in London to demonstrate lower cortisol levels among participants and audience members at community musical performances when compared to control populations [6]. The appreciation of both creating and enjoying music literally makes us healthier. Over and over, we can make the case that we are now scientifically documenting what renaissance physicians intuitively and iteratively understood about the Humanities. This is especially the case when we consider mental health. Multiple scholars have increasingly noted the power of the arts to delineate and ease psychiatric suffering [7].

Given both the history and the growing body of research in support of understanding the Humanities in the pursuit of becoming a physician, one might wonder why this editorial is even necessary. After all, medicine and the Humanities have been combined for thousands of years. There has been consistent support for this intellectual mingling among the most celebrated physicians and scholars, and we have a growing and impressive body of literature in support of furthering these pursuits. Why, then, is there a growing resistance to this ongoing trend?

\section{The Argument Against Humanities in Medical Education}

As our understanding of the physiology of health and wellness has grown significantly over the last few decades, medical schools have found themselves responsible for more and more content. Many have argued that this growing demand for curricular offerings has yielded an increasingly incoherent medical educational structure [8]. From a purely practical standpoint, adding formal exploration of the humanities to an already overly-packed and somewhat scattered medical educational experience further complicates the role of medical educators as they struggle to cover all that modern physicians are expected to know. Moreover, some have taken this argument a step further. They note that the value added by studying the humanities in medical education is relatively small when compared to the cost to students in terms of time, energy, and an already packed schedule.

Finally, there are those with more philosophical and intellectual objections. A recent summary of the future of medical humanities in the UK described the current state of combining humanities with medicine as the "domain of pleasant (but more or less inconsequential) helpmeets - lurking hopefully, poetry books in hand, at the edges of the clinical encounter's "primal scene"' [9]. A different strain of argument involves the overemphasis on narrative approaches to understanding patient care that is often taught in medical humanities programs. Not all people express themselves narratively, and some worry that students who are taught to seek information purely through a narrative format risk empathic failure with the patient as well as missed diagnoses [10]. Finally, many have worried that teaching the Humanities in the context of medicine risks subjecting poetry, literature, and art to the same reductionism that some feel has characterized modern medicine. They argue that poetry and literature need not be useful. The proper role of art is to provoke thought and nothing more. As such, it is misplaced in a medical curriculum, where the goal is first and foremost the mastery of a trade [11].

\section{Why the Humanities Belong in Medicine and Particularly in Psychiatric Education}

As we can see, the history of the Humanities as part of medicine is much like the history of medicine itself. Medical education began the last two centuries with a relatively broad focus, placing the greatest emphasis on the role of the general practice physician or surgeon, and with an appreciation for the importance of an adequate appreciation for the intersection of cultural expectations and medical expertise. To the extent that the Humanities serve as a mirror of both past and present cultural values, physicians were expected to be versed in the Humanities and usually were. Subsequently, as medicine became more technically complex and more highly specialized, some felt that the role of the Humanities in medicine diminished and was therefore less practically addressed. How could reading Plato possibly help a doctor-in-training more than a solid understanding of pathophysiology? And, the more we are required to learn about pathophysiology, the less time we have for Plato. When medical curricula are changed, the subjects for which a clear purpose cannot be easily articulated are 
quick to be removed. Thus, the Humanities find themselves being carved out of modern medical education.

Nevertheless, it is our belief that the Humanities are now more vital than ever to medical endeavors. This is especially the case in psychiatry. We are facing a crisis in medicine, with young doctors reporting record rates of burn-out and an overall sense of lost purpose in their pursuits. The Humanities have been shown to ease or even ameliorate these issues [12].

The Humanities offer a framework through which students of psychiatry can view the existential challenges of self-other dichotomies. The fact that early psychiatrists were called alienists accentuates the extent to which psychiatric illness has often been characterized by the alienation of the self from itself [13]. Edvard Munch's unnerving painting The Scream, or Kafka's unsettling Metamorphosis allow us to grapple with these issues in the displacement that art helpfully affords. Brian Hurwitz [14], a distinguished physician at Kings College in the UK, writes that "productive clinical encounters depend on diverse sorts of communications: spontaneous and staged, verbal and nonverbal, intimate and detached interchanges, observations and intepretations." He goes on to argue that this wide array of nuanced skills is best accomplished by careful study not just of the Humanities, but of the ways in which one studies the humanities. Simply learning pathophysiology and diagnostic skills cannot accomplish this kind of carefully disciplined thinking.

This is the primary argument for the inclusion of the Humanities in psychiatric curricula. More than any other field of medicine, psychiatry finds itself straddling the subjectiveobjective divide.

For example, we can objectively describe depression. We know what depression looks like as a function of a number of criteria that have been accepted into our canon and that we draw upon for our diagnostic and therapeutic initiatives. But depression is also deeply subjective to both the patient and the doctor. The context of the depression, the ways that the psychiatrist might him or herself have been personally affected by depression, the ways that the depression expresses itself within the microculture that creates the world of both the patient and physician - these are all unique and different for each presentation. In this sense, studying psychiatric illness and understanding its many layers are nearly identical to understanding the Humanities. These concepts are extremely difficult to elucidate in the absence of a Humanities framework.

Consider this famous poem:

When, in disgrace with fortune and men's eyes,

I all alone beweep my outcast state,

And trouble deaf heaven with my bootless cries,

And look upon myself and curse my fate,

Wishing me like to one more rich in hope,

Featured like him, like him with friends possessed,
Desiring this man's art and that man's scope, With what I most enjoy contented least; Yet in these thoughts myself almost despising, Haply I think on thee, and then my state, (Like to the lark at break of day arising From sullen earth) sings hymns at heaven's gate; For thy sweet love remembered such wealth brings That then I scorn to change my state with kings. -William Shakespeare, Sonnet \#29

We can literally "diagnose" this poem. It is a sonnet, composed of 14 lines and ending with a rhyming couplet. In fact, we can even characterize its symptoms. Its rhyme scheme makes it a Shakespearean rather than Petrarchan sonnet, and it is certainly nowhere near free verse. In other words, we know the criteria for this to be Shakespearean sonnet. And yet this poem will have unique and special meaning to each person who reads it. That meaning is inextricably tied to the person studying the poem and the ways in which the poem is studied in the first place [15].

This sounds a great deal like the study of depression. We can characterize an agitated depression and differentiate it from a melancholic depression. We can predict the course and prognosis of a given depressive state, but the depression will have special meaning to the patient and the clinician depending on how it is discovered, experienced, and understood. This is in fact the root of a psychiatrist's empathic connection. We connect what we know objectively about an illness with all that we can learn about the patient, ourselves, and our world. Indeed, enhanced empathy is among the most cited reasons for including the Humanities in medical curricula. By teaching the Humanities, by focusing on how humans have for millennia understood what it means to be human, we can impress upon our psychiatric students the exquisite intellectual tension that our field enjoys as it maintains its humanistic core amidst the burgeoning, stunning, and sometimes overwhelming growth of scientific knowledge. The Humanities remind us that there is truth in the subjective as well as the objective. These truths promote empathy, understanding, curiosity, and growth. And these are also the very qualities that make psychiatry so very special.

\section{Compliance with Ethical Standards}

Disclosures The author states that there is no conflict of interest.

\section{References}

1. Bloch S. The art of psychiatry. World Psychiatry. 2005;4(3):130-4.

2. Kelly BD, Feeney L. What every psychiatrist should know. Adv Psychiatr Treat. 2006;12:462-70. 
3. Schlozman S. Humanities and the practice of medicine. Behavior and Medicine, $5^{\text {th }}$ edition. Daniel Wedding and Marge Stuber (Eds.). Hoegrefe. 2010, pp 258-269.

4. Sooke A. Leonardo da Vinci's groundbreaking anatomical sketches. BBC Culture October 21, 2014. Available at http:/ www.bbc.com/culture/story/20130828-leonardo-da-vinci-theanatomist. Accessed 9 Sept 2017.

5. Pitchy Z. Report of the Committee on Medical Education. Trans Am Med Assoc. 1853;6:93-5.

6. Fancourt D, Williamon A, Carvalho LA, Steptoe A, Dow R, Lewis I. Singing modulates mood, stress, cortisol, cytokine and neuropeptide activity in cancer patients and carers. Ecancermedicalscience. 2016;10:631.

7. Crawford P, Brown B, Tischler V, Baker C. Health humanities: the future of medical humanities? Ment Health Rev J. 2010;15:4-10.

8. Lawley TJ, Saxton JF, Johns MME. Medical education: time for reform. Trans Am Clin Climatol Assoc. 2005;116:311-20.
9. Fitzgerald D, Calland F. Entangling the medical humanities in The Edinburgh Companion to the Critical Medical Humanities. ed. Anne Whitehead and Angela Woods. Edinburgh University Press. 2016, chapter 1.

10. Woods A. The limits of narrative: provocations for the medical humanities. Med Humanit. 2011;37(2):73-8.

11. Rothfeld B. The problem with the medical humanities. Hyperallergic 23, 2015. Available at https://hyperallergic.com/ $177969 /$ the-problem-with-the-medical-humanities. Last accessed 9 Sept 2017.

12. Jennings ML. Medical student burnout: interdisciplinary exploration and analysis. J Med Humanit. 2009;30(4):253-69.

13. Clemens NA. The return of the alienist? J Psychiatr Pract. 2007 Nov;13(6):399-401.

14. Hurwitz B. Medicine, the arts and humanities. Clin Med (Lond). 2003;3(6):497-8.

15. Schlozman S. A piece of my mind. The bard in his outcast state. JAMA. 1997;277(14):1118. 